\title{
STUDY OF E-LEARNING SYSTEMS
}

\section{Stanimir M. Sadinov ${ }^{1}$, Jordan H. Kanev ${ }^{1}$}

Technical University of Gabrovo, Gabrovo, Bulgaria

\section{Correspondence:}

Stanimir M. Sadinov

e-mail:

murry@tugab.bg

\begin{abstract}
:
Distance learning is becoming more and more popular every year and it is suitable for people with busy schedules and limited time. At the Technical University in Gabrovo, Bulgaria, we started a project for building an e-learning system, based on learning management systems for distance learning and a new approach in teaching. Our platform is not unified for the whole university at the moment. It is based on Moodle and Ilias LMS and it has some interesting extensions. The aim of this paper is to compare different LMS systems, describe some technical details, encountered differences between these systems and attempt to make them work together.
\end{abstract}

\section{Keywords:}

e-learning, LMS, Moodle, Ilias, virtual library.

\section{INTRODUCTION}

The Technical University of Gabrovo, Bulgaria is an academic and research organization, which provides high-quality education in conformity with the labor market needs for modern broad-profile Bachelor degrees, as well as modern Master and Doctor Degrees in the field of engineering and technologies, business and social sciences. A guarantee for this is the institutional accreditation of the university and the program accreditation of the degree courses in the professional trends for Bachelor and Master and the research programs for Ph.D. degree, granted by the National Evaluation and Accreditation Agency. The quality management system implemented for the training, research and academic staff of the university has been certified according to ISO 9001:2000 and ISO 9001:2008 by DQS GmbH and IQNet. The Technical University of Gabrovo has been accredited by the European Society for Engineering Education IGIP and by the European Federation of National Engineering Associations FEANI.

The university has three faculties - Faculty of Electrical Engineering and Electronics, Faculty of Mechanical and Precision Engineering and Faculty of Economics. Until 3 years ago we had only in-presence learning form.

The project BG051PO001 - 4.3.04 - 0051 "Development and implementation of virtual technologies for sustainably development of distance learning the Technical University of Gabrovo" was initiated and was financed from Human Resources Development Operation Program of 
the Ministry of Labor and Social Policy of the Republic of Bulgaria. It started in October 2012 and finished in October $2014[6,10]$. The e-learning platform is based on Moodle LMS [1], now it is online and it already contains 122 courses from Bachelor's degree programs, master degree programs, modules for alignment of new student's knowledge and also modules developed from business companies. The plan of our university is to offer distance learning in at least three Bachelor and three Master programs.

\section{COMPARISON OF ILIAS, MOODLE, EFRONT}

There are a variety of learning management systems (LMS), like: Moodle, eFront, ILIAS, Docebo, A Tutor etc. Even though they are similar products they all have specific features. Three of the most popular learning management systems are Moodle, eFront and ILIAS. This paper is focused on all three of them and its goal is to present the main features of these systems and show some specifics.

What do all systems have in common?

In order to distinguish the systems, the first common features must be pointed out. All of the three systems are open source and are compatible with the SCORM standard [2]. This standardization guaranties that all content uploaded to certain system can be migrated to all other systems flawlessly. They also have the basic components necessary for online courses and exam conductions: the ability to upload content, testing, surveys, setting exercises, reports and many more.

Users' access to the systems is provided through individual accounts, as the rights of each user are determined by preset in the system user roles. Teacher accounts are able to create courses, upload content and schedule exams. Student accounts can only read specific course content if enrolled and can take exams online.

Other features of the systems:

- Communication means: internal email system, chat, blog, forum;

- Data transfer: wikis, dictionaries;

- Options for issuing certificates;

- Calendar.

The systems are very similar in terms of their components. The systems differ in terms of working logic, the construction of internal content and additional extras.
These components determine the level of difficulty for using any of the systems. After having clarified the common features of the systems, in order to distinguish them from one another we have to point specifics regarding their distinctive characteristics.

\section{ILIAS}

ILIAS [3] is created at the Faculty of Business Administration in Cologne, Germany. The product has good quality and functionality and it meets all needs that the client of LMS may have. It has one disadvantage compared to the other two systems, ILIAS is more complicated, so teachers and students will need more time to become familiar and work with it. But this disadvantage is mainly because it has the largest range of options and work opportunities that makes it the most preferred system when it comes to flexibility and functionality.

The ILIAS platform offers many learning objects and opportunities to make modern and colorful courses. It supports many standard objects, such as tests and learning modules. ILIAS also supports some Web 2.0 features - RSS, podcasting and Google Maps, which can make any training unique in its interactivity. An interesting feature is the ability for using internal and external news channels.

The system can be used as a library and a database, according to user's needs. 27 different kinds of objects can be created in the system and they can be arranged in various combinations. They can serve as data containers, information of different type, users' organization, etc.

This platform is used by various governmental and non-governmental organizations, like NATO, the National Community of American Veterans, Department of Defense - Belgium, Holland, France and others. Its distinctive feature is that it is certified to work with NATO projects, which is indicative for the software quality and security.

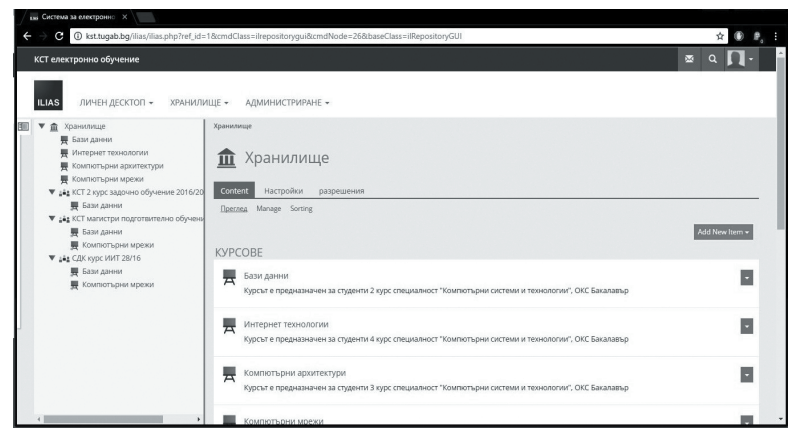

Fig. 1. ILIAS courses overview. 
The installed system in our university is intended for teachers, who intend not only to train their students, but who need long-term storage of archives and data collections [7]. It is installed on new dedicated server with RAID storage array. By the possibilities of using Web 2.0, the system can become something more than an online learning tool. It can hold all discipline materials, student exam score logs, laboratory exercises and "Computer Systems and Technologies" department scientific researcher papers.

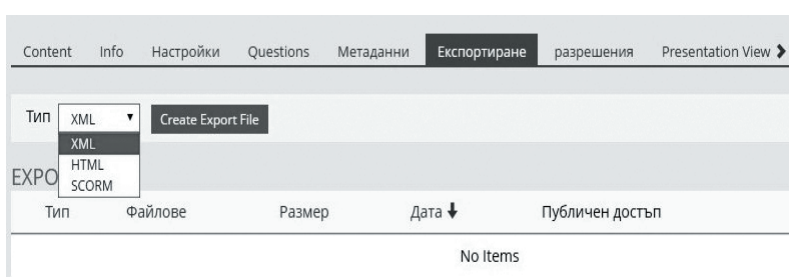

Fig. 2. ILIAS export options.

The main advantage of this system is that all courses can be exported from this platform in XML, HTML or SCORM format (fig.2) and easily deployed in any other learning management system that supports these formats.

Currently there are four IT courses uploaded to this website (fig.1) and the plan is to extend bachelor degree courses to become 22 and 12 master degree courses to be total of 34 courses to the end of this calendar year. These courses cover the full curriculum of "Computer Systems and Technologies" degree course. Our goal is to provide students with quality instructions and skills, which are necessary for their realization as leading specialists in constantly renewing theory and practice in computer systems and technologies. Our graduates are expected to be competent and highly qualified professionals in the field of software and hardware as well as to be prepared to pursue higher education degrees.

\section{EFRONT}

This product is created in 2001 in Greece by Dimitri Tsigos and Anastasios Papagelis [4]. They were driven by customer-focused approach, which makes the system suitable for companies and educational institutions.

Teachers and students can perform the same actions as in the other two platforms, but with a minimum number of clicks, saving time for work and making the study of the system very easy. This is why there is no need for external assistance once the system is put into operation.
There are features like internal email, chat and forum functions implemented in the system, so communication between teachers and students, and between students themselves is easy and convenient.

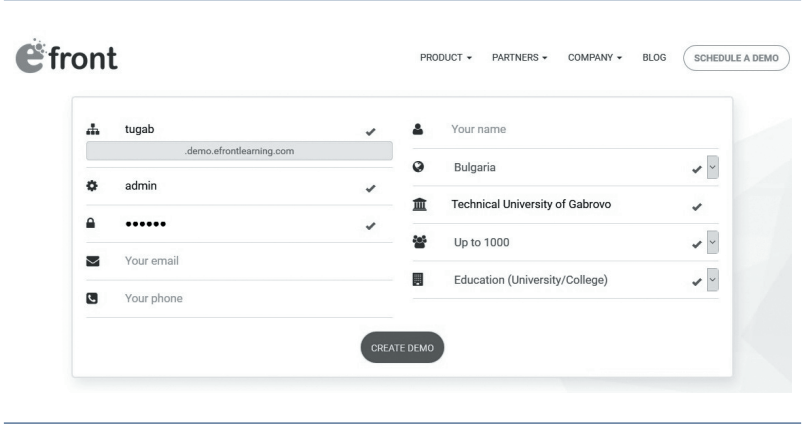

Fig. 3. eFront online testing environment.

eFront is available in three versions: for companies, for educational institutions and for free usage. It is developed according to the specific needs of every client and therefore there are a lot of interesting features. Currently, the system is supported in 50 languages that have two versions - professional human translation and machine translation. Bulgarian language is available only in the machine translation format, so not all menu options are translated correctly and there are some inadequate words. Every language can be added to the platform very easily just by downloading it from the web site and uploading it on the system.

Our first glimpse of this product was via online demo presented by vendor website (fig.3) [5]. There are some limitations using this demo version, i.e. there is no way to install different languages and not all features are available, so in order to test its full capabilities we had to install it on our own server (fig.4). Once we had installed in on our datacenter server we were able to localize interface in Bulgarian and experience the full set of capabilities of this system.

The platform eFront is very easy for use. Its interface is very clean, simple and straight forward.

The software is extremely suitable for all kinds of companies, educational institutions and organizations that experience the need to conduct online courses and test their learners' knowledge. 


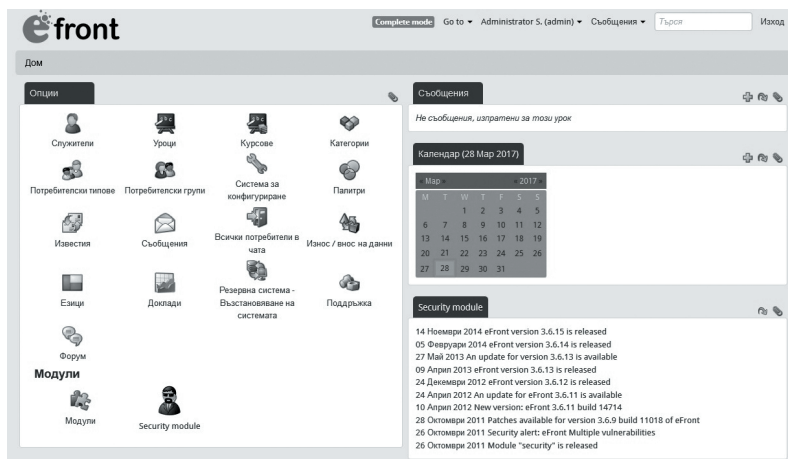

Fig. 4. eFront administrative interface.

\section{MOODLE}

According to many sources Moodle is the world's leading company dealing with educational and technological consultations and leading position in learning management systems ratings, preferred by the universities for the high results that the systems performs. One of the reasons that make this platform so desirable by educational institutions is the fact that it supports over 100 languages.

The Moodle system [1] is quite suitable for both individual teachers and universities with thousands of students. Nowadays, the platform is used by hundreds of universities in Australia, America and Europe, such as London School of Economics and Political Science, University of Sydney, Brigham Young University, California State University, etc. In Bulgaria it is used at Sofia University and also at Technical University of Gabrovo since 2014 year [10].

The main idea that resulted in creating this platform was to make it useful for different kinds of educational institutions: schools, universities, etc. Because of this reason, teachers can easily put and structure learning content and their students can easily find the way to it and get the maximum of the learning process. There is also a possibility to import and export different content and teachers can utilize any HTML, PDF or SCORM [2] material.

The Moodle system is being developed to be oriented towards creation of community of Moodle users, where users and creators can communicate and help each other. Developers, on the one hand, assist users in the usage of all system features and on the other hand, take their ideas for improvements. There are a lot of books and tutorials explaining the structure and features of Moodle learning management system [8].

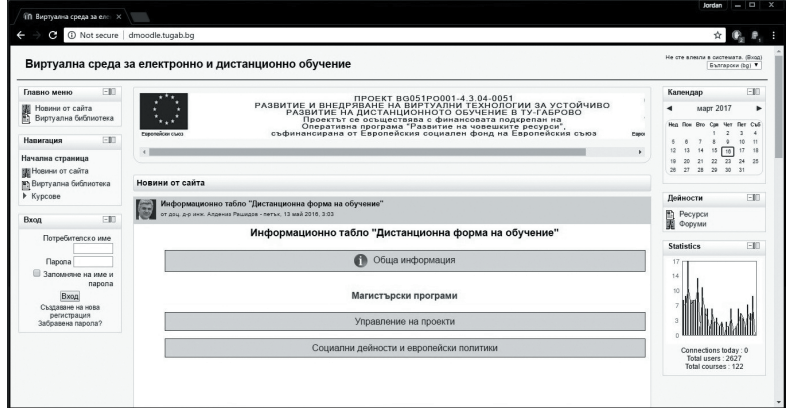

Fig. 5. Moodle main view.

When this platform was for the first time introduced at our university it was selected because it was an open source and free of charge. The version used at the time was 2.3, which was the last stable one by the end of the year 2012 [10]. During the summer of 2014 it was upgraded to the most recent version available at the moment. It was running on Windows 2008 R2 Server with Apache web server, MySQL database and PHP. Last year it was migrated to a new server with virtualization and runs on Windows 2012 Server. All modules were updated to latest versions too. At the moment this is the main distance learning platform at our university. The e-learning system can be reached at the address http://dmoodle.tugab.bg [6]. Its main screen is shown at Fig. 5.

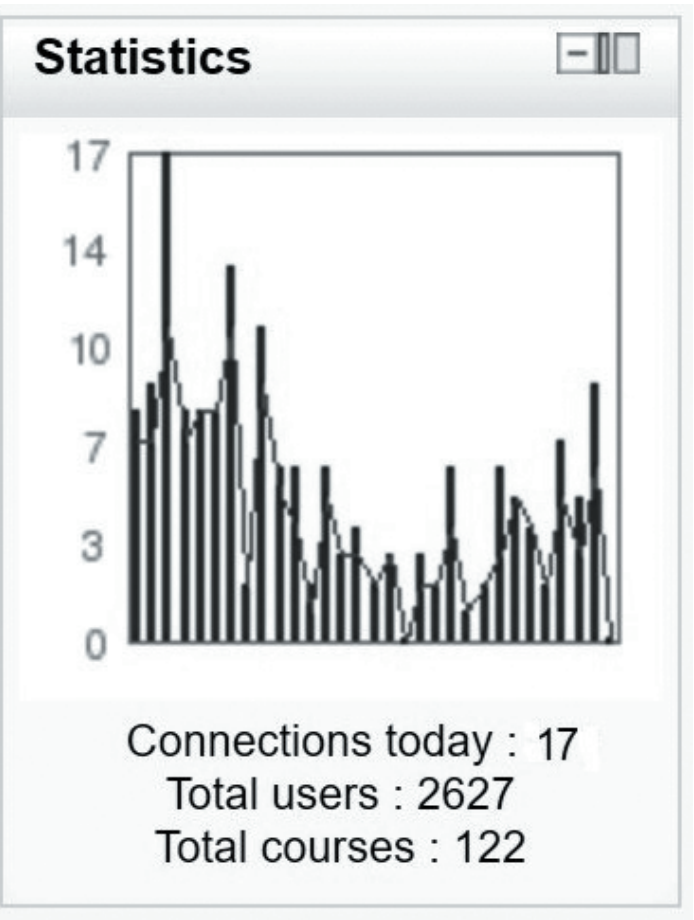

Fig. 6. Moodle statistics module. 
The statistics module became necessary, because we needed to find a way to prove to the ministry the actual count of students who have taken some courses, the actual time every student spent on the course and the results achieved. For this we used the standard Moodle plugin - Graph Stats (block_graph_stats) [9, 10]. This module can be downloaded from the Moodle plugins directory and must be installed in the standard way for installing plugins in Moodle. It displays a little graph with visitors' statistics, as shown in Fig. 5 and 6. Parameters like size, colors, style, number of days and engine used (Moodle/ Google) are configurable and can be changed as needed.

We believe that Moodle is very suitable for educational institutions and educational companies of all types and sizes.

\section{CONCLUSION}

These three learning management systems are widely used not only around the world, but also here, in Bulgaria. They have many features that simultaneously unite and differentiate them. The choice witch one to use depends on your own objectives and needs. We hope that this paper helped understand some of the advantages, offered by the online learning systems and the three systems in object of study.

This paper describes the initial challenges, building process and content, some technical details, and some practical extensions of the e-learning systems functioning at the Technical university of Gabrovo. Introduction and implementation of e-distance learning as a new form of teaching and learning improves the quality of education and lays the foundation for long-term and sustainable development in accordance with the new requirements of the labor market. It must therefore be concluded that the commercial firms directly related to the Technical University of Gabrovo improve the quality of their products and services. Expansion of educational opportunities like implementation of distance eLearning entails the need of educational infrastructure development. The based virtual library, providing a broad and easy access to information and educational resources, as well as expanded and adapted learning and information system along with quality management are adequate and innovation open responses to new educational needs of students. The wide applicability of the established practices of e-distance learning in the various disciplines of the pilot as well as the development of activities planned for a long period after the project ended, lead to the conclusion that the nature of the training form is highly adaptable and implemented in time. Expansion of educational services in different directions gives a significant impact on the development of university social capital.

Realization of distance learning modules, integrated in information database of all university departments will provide better communication between teachers, students and $\mathrm{PhD}$ students and will help their collaboration in the future.

Creation of such an infrastructure is crucial in modern high-tech world, where everything around us is digitalized.

The advantages of implementation of distance learning courses in education are:

- Achievement of high level of psychological comfort with information presented in a user friendly way, in convenient time period and on all sets of end user devices;

- Ensuring good material absorption by using different forms of representation of educational content, assigning homework independently, ensuring systematic monitoring and more.

- Ensuring productive dialogue training through a variety of interactive tools and student feedbacks;

- Easy manageability of content - wide opportunities for expansion and management of the learning database;

- Presence of the collaboration of all possible kinds and individual selection of the most suitable of them;

- Optimal combination of different types of work - collective, private, under the supervision of a mentor and others.

Conducted theoretical and experimental studies have shown the beneficial effects of the introduction of information-based educational modules related to the planning and construction of communication networks of different types. Good network planning is linked to compliance with all necessary parameters, which requires good knowledge of all existing standards. This can be achieved through the use of easy accessible eLearning databases with flexible search capabilities.

\section{ACKNOWLEDGMENT}

The work presented in this paper is supported with the assistance of two projects:

Project 1712E "Creating innovative information based educational training modules in communication techniques and technologies field" 
Project 1709E "Development and implementation of innovative IT technologies in education"

Both projects are from the University Center for Research and Technology at Technical University of Gabrovo.

\section{REFERENCES}

[1] Moodle, "The Moodle Project", https://moodle.org/, date of use 14.02.2017

[2] What is SCORM?, "Rustici Software", http://scorm. $\mathrm{com} /$, date of use 20.02.2017

[3] ILIAS, "ILIAS Open Source E-Learning", http:// www.ilias.de/, date of use 22.02.2017

[4] eFront, "eFront Open Source LMS" https://www. efrontlearning.com/, date of use 20.03.2017

[5] eFront online demo registration, "eFront online Demo system" http://tugab.demo.efrontlearning. $\mathrm{com} /$, date of use 22.03.2017.
[6] Virtual platform for electronic and distance education, "Виртуална среда за електронно и дистанционно обучение”, http://dmoodle.tugab. $\mathrm{bg} /$, date of use 06.03.2017.

[7] CST Department electronic education system, "КСТ електронно обучение", http://kst.tugab.bg/ ilias/, date of use 07.03.2017.

[8] J. Cole and H. Foster, "Using Moodle", 2nd ed., O'Reilly Community Press, November 2007, ISBN13: 978-0-596-52918-5.

[9] Moodle plugins, "Blocks: Statistics (Graph Stats)", $\quad$ https://moodle.org/plugins/view. php?plugin=block_graph_stats, date of usage 21.03.2017

[10] D. Genkov, V. Kesova "Building an e-learning system in Technical university of Gabrovo, Bulgaria", In Proceedings of EDULEARN 14 Conference, 07 - 09 July 2014, Barcelona, Spain, 2014, ISBN 97884-617-0557-3, pp. 619 - 626. 